\title{
O TRABALHO DA ENFERMAGEM EM CENTRO CIRÚRGICO - ANÁLISE DE DEPOIMENTOS
}

Rosalina Aparecida Partezani Rodrigues*

Fátima Aparecida Emm Faleiros Sousa*

Os autores relatam nesse artigo o trabalho da enfermeira no centro cirúrgico ou seja, os objetos de trabalho, os instrumentos, o produto e suas finalidades.

Unitermos: Processo de trabalho, enfermeira, enfermagem em centro cirúrgico

\section{INTRODUÇÃO}

No que tange ao conhecimento de prática, CARVALHO \& CASTRO (1979) interpretam-na como sendo o "significado de uma profissão na sociedade, porque nela se consubstancia a realização do compromisso social, o qual, sendo obrigatório e coletivo, garante à profissão sua continuidade no tempo".

Para ALMEIDA $(1985,1986)$, a prática de enfermagem é entendida como o "conhecimento ( saber da enfermagem) corporificado em um nível técnico (instrumentos e condutas) e relações sociais específicas, visando ao atendimento de necessidades humanas, que podem ser definidas biológica, psicológica e socialmente".

ALMEIDA e cols. (1989) ainda concebem a prática de enfermagem como prática social e, portanto, historicamente estruturada e socialmente articulada. Ela é constitutiva das práticas sociais em geral e das práticas de saúde em particular.

A referida autora procede a uma reflexão da evolução histórica da prática de

*Professor Assistente do Departamento de Enfermagem Geral e Especializada da Escola de Enfermagem de Ribeirão Preto - Universidade de São Paulo 
enfermagem em seu trabalho "O saber da Enfermagem a sua dimensão prática". no qual relata que a profissão está relacionada aos fatos sociais de cada período e que a prática tanto da saúde como da enfermagem está ligada ao processo de mudança social, fator este determinante nesta prática, que se estabelece em um período numa dada sociedade.

Na América Latina, a partir de 1960, com o desenvolvimento e a modernização dos hospitais foi centrada a atenção à saúde na área curativa e, por sua vez, a prática da enfermagem também se desenvolveu nessa área.

ALCANTRA (1963) refere que "os novos estabelecimentos hospitalares passaram a constituir maior mercado para as enfermeiras diplomadas, relegando a plano secundários os serviços de saúde publica". Ainda a autora assinala ter encontrado em 1950, 49,4\% das enfermeiras no campo hospitalar e $17,2 \%$ no campo da saúde pública em nosso país.

O trabalho da enfermagem é parte integrante do processo de trabalho em saúde, tanto no modelo de assistência individual como coletiva (CASTELLANOS e cols.,1989) por sua vez são partes complementares de um mesmo trabalho. Em se tratando do processo de trabalho em Centro Cirúrgico este tem por objetivo a assistência curativa, individualizada.

O trabalho da enfermeira de Centro Cirúrgico nasceu para atender às necessidades da equipe cirúrgica, isto é, houve a necessidade de desdobrar o trabalho médico ao organizar uma unidade onde fossem realizadas as cirurgias, bem como o preparo de material e equipamentos indispensáveis ao procedimento cirúrgico. Segundo CORREIA (1978), a enfermeira assumiu a prática no Centro cirúrgico, apenas para fiscalizar o serviço de enfermagem, no sentido de verificar o cumprimento adequado das técnicas.

A prática da enfermeira em centro cirúrgico estava mais voltada para os aspectos de gerenciamento, ou seja, para a provisão, o manuseio, e a manutenção de materiais e equipamentos nas salas de operação.

JOUCLAS (1987) refere que o desenvolvimento das técnicas cirúrgicas e os procedimentos anestésicos tiveram seu marco no final dos anos 60 e início de 70 . O centro cirúrgico, por sua vez, estava se tornando uma unidade de alta tecnologia, necessitando estar preparado para o atendimento das mais sofisticadas cirurgias, como os primeiros transplantes de rim e de coração.

Através dos relatos de JOUGLAS (1987) percebemos que a prática da enfermeira em centro cirúrgico, também se relaciona com as primeiras expressões do saber da enfermagem citadas por ALMEIDA (1986), como sendo constituídas pela execução das técnicas em enfermagem.

Outrossim, observamos que após esse período, (década de 60/70), surgiram os princípios científicos relacionados à assepsia cirúrgica, os quais contribuíram para a evolução da prática em centro cirúrgico.

A questão da prática da enfermeira vem sendo indagada no que se refere ao objeto de trabalho, nos níveis da assistência, do ensino e da pesquisa. Assim, fizemos um recorte da prática de enfermagem e optamos por estudar somente o trabalho da enfermeira de centro 
cirúrgico, devido ao nosso interesse nesta área específica.

Assim, o objetivo deste estudo é analisar o trabalho da enfermeira em centro cirúrgico, no ano de 1988, na cidade de Ribeirão Preto, São Paulo, ou seja seus objetos de trabalho, instrumentos, produto e finalidades.

\section{1 - A Enfermeira e o trabalho no Centro Cirúrgico}

Para MARX (1985) o trabalho é social e a essência do ser humano está no trabalho. Para ele, o "trabalho é um processo do qual participa o homem e a natureza". É na relação do homem com a natureza que ocorre o processo de produção, de reprodução e da existência (bens e serviços). Nesse processo de produção, de reprodução e da existência determinada pelo grau de desenvolvimento das forças produtivas, geradas pelas primeiras necessidades."

MENDES-GONÇALVES (1988), refere que é pelo processo de trabalho com seus elementos constitutivos, quais sejam, o objetivo de trabalho, instrumento de trabalho, produto e finalidade, que o homem transforma a natureza.

Objetivo de trabalho "são todas as coisas que o homem apenas separa de sua conexão imediata com o seu meio natural". O objetivo já contém em potencial o projeto do produto, ou seja, o "produto virtual" (ALMEIDA et al., 1989).

A transformação do objeto de trabalho em produto se faz através de um gasto de energia que entra no processo sob a forma de instrumento. "O instrumento representa o ponto de encontro do produto que contém as necessidades e a finalidade do trabalho, portanto é regida por um plano preestabelecido de transformação". (ALMEIDA et al., 1989). São características essenciais do trabalho humano, a socialidade e a historicidade.

Como o homem é social, a satisfação de suas necessidades ocorre através do trabalho, para atender às finalidades específicas, resultante das necessidades coletiva (MENDES - GONÇALVES - 1988).

A historicidade é a segunda característica do trabalho que identifica as necessidades humanas e as satisfaz. Estas correspondem aos carecimentos não individuais, mas coletivos e, como tal estão em constantes mudanças. Assim, a maneira de satisfazê-las também varia, e as relações sociais de produção, advindas daí são contraditórias. Dessa forma, o trabalho humano é sempre histórico (MENDES - GONÇALVES, 1988).

CASTELLANOS (1987), refere que as funções da enfermeira estão relacionadas a um processo histórico e social condicionados à visão de mundo - do homem enquanto ser com seus valores, seus ideais e da própria profissão - a enfermagem.

Para a compreensão do trabalho da enfermagem faz se necessário olhar para o processo de trabalho em saúde e MENDES-GONÇALVES (1988) relata dois modelos tecnológicos: 
* epidemiológico - no qual procure-se controlar a doença no meio social, evitando a incapacidade para o trabalho, correspondendo este ao modelo de assistência em saúde coletiva.

* clínico - o fundamental neste modo é recuperar a força de trabalho oferecendo condições para que o trabalhador retorne ao processo produtivo, correspondendo este ao modelo individual de assistência.

Portanto, o trabalho que vamos discorrer neste estudo será o relacionamento especificamente com o modelo clínico (individual), centrado na área hospitalar, enfatizando a unidade de centro cirúrgico.

O centro cirúrgico é uma área física do hospital, com uma equipe multiprofissional equipamento e material de consumo adequado à execução do processo cirúrgico, sendo que a sua finalidade é fornecer subsídios que propiciem o desenrolar do processo do ato terapêutico - a cirurgia - oferecendo condições para que a equipe médica e de enfermagem possam planejar as necessidades dos pacientes antes, durante e após a cirurgia.

O trabalho no centro cirúrgico faz parte do trabalho em saúde e tem como característica o trabalho coletivo, realizado por vários profissionais como os cirurgiões, anestesistas, técnicos de $\mathrm{Rx}$ e de laboratório, dentre outros e também a equipe de enfermagem subdividida em quatro categorias: enfermeiras, técnicos, auxiliares e atendentes de enfermagem, todos ocupando o mesmo espaço, mas com uma divisão técnica de trabalho onde cada um exerce uma determinada tarefa.

Segundo entrevista feita a BRANDANI (1988)**, o início da prática da enfermeira em centro cirúrgico no município de Ribeirão Preto desenvolveu-se a partir da criação da Faculdade de Medicina e da Escola de Enfermagem. Segundo a entrevistada, atuando no centro cirúrgico com outras enfermeiras, perceberam que essa nova tarefa exigia-lhes maior aprimoramento de conhecimentos técnicos. Assim, buscaram-no através de visitas e outros centros, levantamentos bibliográficos e orientações médicas.

Com a criação da Escola de Enfermagem, a Diretora desta unidade trouxe enfermeiras da capital do Estado para atuarem no Hospital e exercerem a função de docente. A prática da enfermagem cirúrgica, especificamente em centro cirúrgico, estava voltada para o ensino e a assistência. Crescendo a demanda de alunos de alunos nesta Escola, gerou-se a necessidades da atuação das docentes no Hospital apenas por um período parcial, havendo, dessa forma, a necessidade de contratação de uma enfermeira recém formada para o desempenho das funções junto ao centro cirúrgico.

\footnotetext{
** Entrevista realizada com Lara Brandani, umas das primeiras enfermeiras que trabalhou no Centro Cirúrgico em Ribeirão Preto. S/P
} 


\section{METODOLOGIA.}

Para o estudo da prática da enfermeira em centro cirúrgico foram utilizadas como referências as categorias do processo de trabalho formuladas por MARX (1985) e utilizada na enfermagem por ALMEIDA et. al. (1989).

Os componentes do processo de trabalho são constituídos pela matéria que se aplica ao trabalho, os meios ou instrumentos do trabalho.

Para a coleta de dados foi utilizado um instrumento, constando esse de duas etapas sendo a primeira relacionada à identificação do profissional e a segunda a um questionário semi-estruturado com itens abertos, a respeito da prática da enfermeira na referida unidade em estudo.

O instrumento foi aplicado em 17 enfermeiras, as quais trabalham em unidade de centro cirúrgico dos hospitais gerais do município de Ribeirão Preto, individualmente, pelas pesquisadoras.

Foi utilizado também um roteiro para observação da prática das enfermeiras em um dos centros cirúrgicos estudados. A realização da observação em apenas um dos hospitais estudados foi um dos limites deste trabalho, mas optamos por fazê-lo porque é real, direto e a luz do processo de trabalho, porque a representação é um processo de reconstituição que contém tanto o fazer como o dizer (discurso) (MAGNANI, 1986).

Um dos objetivos da observação foi identificar o processo de trabalho da enfermeira em centro cirúrgico. Para realizar este procedimento utilizamos um roteiro de observação sistematizado, registrando a localização do sujeito, isto é, a enfermeira trabalhando no centro cirúrgico de um determinado hospital da cidade de Ribeirão Preto.

A técnica utilizada pelas pesquisadoras foi a de registro contínuo. "Registro contínuo consiste em um período ininterrupto de observação, registrar o que ocorre na situação, obedecendo a seqüência temporal em que os fatos se dão (DANNA, 1984).

A análise desta prática da enfermeira em centro cirúrgico nos hospitais gerais de Ribeirão Preto - SP seguiu inicialmente a identificação das profissionais e a seguir, o processo de trabalho das enfermeiras, qual seja seu objetivo, instrumentos, produto e finalidade desse trabalho.

Para a análise dos dados segui-se os passos propostos por MINAYO (1992): ordenação dos dados: as entrevistas foram ordenadas, realizadas as leituras e organizados os dados; classificação dos dados: foi realizada de acordo com as categorias do referencial teórico. Após essas duas etapas foi realizada a análise final, de acordo com o referencial proposto. 


\section{RESULTADOS E DISCUSSÃO}

\section{1 - Identificação dos Profissionais.}

No município de Ribeirão Preto, em 1988 existiam 405 enfermeiros, das quais 349 $(86,1 \%)$ atuantes nos hospitais onde coletamos os dados. Desse total, $23(5,6 \%)$ desenvolviam sua prática na unidade de centro cirúrgico, sendo que a coleta de dados foi realizada com apenas 17 enfermeiras, em virtude de que 06 delas encontravam-se afastadas do trabalho.

Verificamos que, 14 (82,3\%) estão na faixa etária dos 20-30 anos; 2 (11,7\%) na faixa etária dos 30 - 40 anos e apenas 1 (5,8\%) na faixa etária acima de 40.

Quanto ao sexo, as 17 (100\%) enfermeiras do centro cirúrgico são do sexo feminino.

Em relação ao tempo de trabalho, verificamos que 5 (29,45\%) têm de 5 meses a 2 anos; $5(29,45 \%)$ de 2 a 5 anos e $7(41,1 \%) 5$ anos ou mais de prática hospitalar.

Quanto ao tempo de prática como enfermeira de centro cirúrgico registrou-se que 11 $(64,8 \%)$ cursaram Médico-Cirúrgica, 2 (11,7\%) Saúde Pública e 4 (76,4\%) têm jornada de trabalho até 36 horas e $4(23,6 \%) 40$ horas semanais.

Os dados nos mostram que quanto ao salário recebido pelos enfermeiros 13 (76,4\%) estão na faixa de 4 a 6 salários mínimos e 4 (23,6\%) de 6 a 8 salários mínimos.

Verificamos que a população é jovem, no que diz respeito à faixa etária, e também quanto ao tempo de prática em centro cirúrgico. A grande maioria cursou habilitação em enfermagem Médico-Cirúrgico. A grande maioria cursou habilitação em enfermagem Médico-Cirurgia, sendo essa coerente com a prática atual e, apenas uma pequena parcela tem curso de especialização.

\section{2 - O Processo de trabalho da Enfermeira em Centro Cirúrgico}

\section{* Objeto de Trabalho}

No que se refere ao processo de trabalho humano, MENDES-GONÇALVES (1988) coloca que ao "recortar um certo objeto separando-o de sua conexão imediata com o meio natural, obtém-se o objetivo de trabalho (O.T.), e com este recorte delineia-se o projeto do 
produto (P.) e este por sua vez conterá a realização das potencialidades inscritas no objeto de trabalho, bem como a satisfação potencial dos carecimentos (N.) que desencadeiam todo o processo."

Isto posto, o objeto de trabalho da enfermeira em Centro Cirúrgico no final da década de 1950 era a "organização do ambiente em que o docente estava inserido", o "cuidar" do paciente e o "administrar" o centro cirúrgico.

Na década de 1950 e 1960 e enfermagem se institucionalizou no Brasil de uma forma marcante, principalmente nos grandes Hospitais das capitais. A tecnologia teve uma repercussão acentuada nessas instituições e a prática da enfermeira evidenciou-se em um novo ambiente, o centro cirúrgico, exigindo uma outra compreensão do processo de trabalho.

O objetivo de trabalho da enfermeira de centro cirúrgico no ano de 1988 é a organização do ambiente quanto à limpeza da sala, dos materiais e esterilização dos instrumentos médico-cirúrgicos proporcionando meios para o cirurgião realizar 0 ato cirúrgico. O produto do trabalho da enfermagem em determinado momento passa a ser instrumento do trabalho médico.

TREVISAN (1988) em seu estudo relata que a função burocrática da enfermeira é comandada pelo compromisso com a organização, mantendo-a submissa às regras, normas e rotinas. A administração, coordenação das várias atividades e providências de recursos humanos e materiais é um dos instrumentos para se atingir a finalidade: a transformação no corpo biológico do cliente através do ato cirúrgico.

Com vistas à prática exercida pelas enfermeiras, verificamos nesse estudo, que a mesma está voltada para o aspecto administrativos e coerentes com os objetivos da instituição. Percebemos dessa forma, a não existência de planejamento para a prática administrativa; há um distanciamento entre as verdadeiras necessidades e a prática realizada, notando-se assim a maior preocupação com a solicitação médica.

A função burocrática da enfermeira predomina, sendo que essas referem sentir-se "sobrecarregadas, no sentido de terem várias coisas ao mesmo tempo para serem resolvidas," portanto, vista pelas mesmas como "falha" essa função.

Quanto ao "administrar", ainda nos depoimentos é relatado que, "uma vez realizado o planejamento administrativo de forma coerente, haverá espaço para assistência ao paciente cirúrgico; "que é cobrado muito da enfermeira "iniciativa e decisão para responder às exigências dos cirurgiões e da instituição" e, que esta muitas vezes sente-se "fiscalizadora e controladora" do processo de produção e "supervisora do pessoal de enfermagem".

Percebemos, através das falas das enfermeiras, que o planejamento, a organização, o comando, o controle e coordenação estão incorporados no seu trabalho diário, segundo a teoria de FAYOL (1968).

No que se refere ao objetivo de trabalho - "cuidar" - percebemos que no ano de 1988, este objeto de trabalho não está presente, o que pode ser constatado pelas falas das enfermeiras e pela observação. 
$\mathrm{Na}$ prática do "cuidar" assiste-se a um afastamento entre enfermeira e paciente, sendo que muitas vezes a primeira "não tem oportunidade de ver o paciente"; freqüentemente eles são tratados "como caso" e não como pessoas. Em geral, as enfermeiras delegam o "cuidar" do paciente cirúrgico aos "ocupacionais de enfermagem que, por sua vez, não estão preparados para assisti-lo. O "cuidar" visa apenas a técnica e os princípios científicos, com vistas à assepsia do procedimento. Verificamos que, na prática diária, a enfermeira refere que "não tem tempo para dar cuidado ao paciente".

Ainda sobre o "cuidar" as mesmas referem que "o contato com o paciente é mínimo, geralmente na recepção do centro cirúrgico, quando é possível" ... "não há trabalho de acompanhamento ao paciente nos períodos pré, trans e pós operatório" e a enfermeira tem consciência que falta um planejamento da assistência ao paciente no período transoperatório"... e não é "explicado ao paciente o procedimento a que será submetido" e ...há o reconhecimento de que essa "assistência é fragmentada"...Outro aspecto considerado também é que "o médico não espera a enfermeira conversar com o paciente cirúrgico, que "as atividades burocráticas são muitas", que "não sobra tempo para a assistência" e o "número de enfermeiras que atuam no centro cirúrgico é mínimo."

\section{* Produto e Finalidade}

Em relação à "transformação do objeto de trabalho em produto, esta se faz através de um gasto de energia que entra no processo sob a forma de instrumentos de trabalho (ALMEIDA e cols., 1989).

Dessa forma, vamos rever que o objeto de trabalho da enfermeira no ano de 1980 era a "organização do ambiente em que o docente estava inserido" e entendemos que o produto esperado, ou seja "a manutenção do paciente no ambiente da sala de cirurgia livre de infecções", promovendo dessa forma um ambiente asséptico.

Cabe salientar ainda que, o planejamento e execução dos procedimentos técnicos devem ser o mais rigoroso possível com relação a limpeza do ambiente, anti-sepsia, assepsia e toda tecnologia envolvida no centro cirúrgico.

As atividades administrativas realizadas pelas enfermeiras de centro cirúrgico ficam muito claras nas suas representações, "sendo consideradas necessidades da instituição". mas são, na realidade, necessidade do processo de trabalho. A finalidade do ato cirúrgico exige este processo. Percebe-se que, a administração da enfermeira está coerente com as necessidades da instituição. Vale ressaltar que, JOUGLAS (1987) aborda em seu estudo, que a enfermeira de centro cirúrgico surgiu para organizar o ambiente cirúrgico, isto é, para a provisão, o manuseio e a manutenção de materiais e equipamentos da sala de cirurgias, e permanece até os dias de hoje, com uma gama de recursos tecnológicos bem mais sofisticados. 
Dessa forma, fica caracterizada a finalidade do trabalho da enfermeira em centro cirúrgico como sendo "a organização do ambiente do centro cirúrgico", isto é, a organização do processo de cuidar, coordenar e controlar o trabalho da equipe de enfermagem e também as atividades que o centro cirúrgico mantém com outras seções do hospital, para complementar o projeto médico.

\section{* Instrumento de Trabalho}

Os instrumentos de trabalho são utilizados para apreender e transformar o objetivo de trabalho.

Para MARX (1985), instrumento de trabalho "é uma coisa ou complexo de coisas, os trabalhadores inserem entre si mesmo e o objeto de trabalho e lhes serve para dirigir suas atividades sobre esse objeto (...), um órgão que acrescenta a seus próprios órgãos corporais".

No trabalho da enfermaria de centro cirúrgico, os instrumentos, que identificamos através da representação das enfermeiras utilizadas para a realização de processo de trabalho destas, foram os envolvem o paciente, como a organização do ambiente, por exemplo.

O trabalho da enfermagem em centro cirúrgico é especializado e coletivo, sendo que cada elemento desempenha uma tarefa, havendo assim uma divisão ao trabalho. Percebese que, a enfermeira de centro cirúrgico não só utiliza alguns instrumentos de trabalhos, mas também, transfere o manejo e a execução destes para o atendente e auxiliar de enfermagem dando conta assim do projeto de trabalho médico, isto é, da cura dos corpos dos pacientes cirúrgicos e também da finalidade do trabalho da enfermeira - organização do ambiente, o cuidado e a administração.

Os instrumentos de trabalho que abordaremos na área de enfermagem em centro cirúrgico serão relatados, segundo as falas das enfermeiras, de acordo com objeto de trabalho... "organização do ambiente em que o doente está inserido, o cuidado e a administração". O aparecimento de novos instrumentos de trabalho da enfermeira em centro cirúrgico surgiu graças ao desenvolvimento do conhecimento que, no caso da microbiologia tem um papel fundamental - a limpeza do ambiente cirúrgico, anti-sepsia, assepsia e esterilização - tendo este avançado muito nas últimas décadas, reduzindo assim o índice de infecção do paciente cirúrgico no período trans-operatório.

Quando à organização do ambiente, o conhecimento cientifico sobre a assepsia, anti-sepsia e esterilização são "importante para os meios de trabalho da enfermeira" e que é "importante o controle rigoroso da esterilização dos materiais e seu manuseio", para a prevenção e controle da infeção... e assim "toda a equipe deve paramentar-se e aplicar as técnicas corretamente".

Quanto ao conhecimento, são ressaltados também o aprofundamento quanto à 
fisiopatologia e à técnica... as enfermeiras relatam que recorrem a livros e revistas", procuram "visitar outros centros cirúrgicos com o objetivo de aprimorar os conhecimentos nessa área", ainda participam "de eventos científicos" e também verificamos, através da observação, que as mesmas "solicitam orientação aos cirurgiões e também aos demais elementos da equipe de enfermagem".

Estando a enfermeira inserida no centro cirúrgico, unidade esta que envolve uma alta tecnologia, instrumentos de trabalho devem ser utilizados para acompanhar os avanços tecnológicos no setor saúde, favorecendo assim uma maior segurança e rapidez no atendimento ao paciente cirúrgico. O uso destes instrumentos é bem evidente em todos os centros cirúrgicos estudados..., sendo relatado pelas enfermeiras que "a cada momento recebemos um aparelho novo e necessitamos estudá-lo, desde o seu funcionamento até a sua utilização "... ou ainda... "a tecnologia é importante pois oferece uma assistência mais qualificada ao paciente".

Concomitantemente com a tecnologia, o desenvolvimento e o aprimoramento das técnicas também foram observados. Por exemplo, o rigor com que a enfermeira solicita aos seus funcionários no que se refere "a assepsia" na execução das técnicas, promove assim segurança ao paciente. O controle de infecção é fundamental no processo de trabalho em centro cirúrgico.

O controle para evitar infecção parece-nos que é o ponto mais importante para a enfermeira de centro cirúrgico, enquanto que para são o diagnóstico e a técnica cirúrgica.

Outro instrumento identificado foi a observação. A observação é um instrumento que possibilita a capacidade de reflexão, julgamento e tomada de decisão da enfermeira em centro cirúrgico, o qual deve permear todos os momentos do trabalho..., uma vez que uma pequena falha na identificação do paciente "ou na "colocação de um aparelho errado", ou "colocação da placa de bisturi, derramando anti-séptico" ou ainda "material inadequado para cirurgia", são fatores que podem prejudicar o paciente. A observação é um dos instrumentos de trabalho que permeia toda a unidade - a organização de todo o ambiente, o cuidado ao paciente também está presente na administração. O administrar é um meio para a transformação do ato cirúrgico.

A comunicação tanto escrita como verbal também identificada como um instrumento de trabalho tanto da enfermeira quanto da equipe de trabalho de centro cirúrgico. Todo aspecto de organização do ambiente, cuidado com o paciente e gerenciamento da utilidade tem como ponto de referência a comunicação. "depende dos elementos que compõem a equipe".

As enfermeiras relatam "que deve haver uma comunicação efetiva no centro cirúrgico"... caso contrário... "serviço não anda".

A operacionalização das normas e as rotinas também foram observadas por nós e relatadas pelas enfermeiras em sua prática profissional. 
As normas e rotinas no centro cirúrgico compreendem um conjunto de medidas relativas a "uniforme próprio para o centro cirúrgico, horário de funcionamento que deve ser rigoroso, escalas cirúrgicas que devem ser elaboradas com 24 horas de antecedência, materiais e equipamentos que devem estar disponíveis tanto em qualidade, como em quantidade para o processo cirúrgico, desinfecção do ambiente cirúrgico, teste de seleção de materiais e controle das cirurgias suspensas"... As normas e rotinas na unidade de centro cirúrgico são seguidas com muito rigor, pois... "o paciente cirúrgico deve receber o melhor tratamento possível", favorecendo assim a qualidade da assistência, bem Como o andamento do serviço. As normas e rotinas possibilitam a previsibilidade, isto é, todas as ações são previsíveis por todos. Como é um trabalho coletivo, parcelado entre vários agentes, isto se faz necessário.

O bom senso também ocorreu em alguns momentos dos relatos realizados pelas enfermeiras como... "vamos aguardar a cirurgia terminar para tomarmos uma postura "... ou ainda "vamos aguardar o cirurgião checar para chegarmos a uma conclusão melhor. Acreditamos que o bom senso é um instrumento de trabalho que deve permear todo o processo de trabalho de enfermeira... "as decisões devem ser tomadas com cautela e com muita reflexo por nós"...

O processo administrativo é utilizado em todos os momentos do processo de trabalho de enfermeira de centro cirúrgico. TREVISAN (1988), referindo-se ao trabalho de FAYOL (1968) argumenta que se focaliza a estrutura formal da organização e "sua teoria do processo administrativo se fez presente na organização hospitalar... orientando as funções de seus administradores e abrangendo horizontes mais amplos de modo a visualizar o hospital como um todo orgânico, sistêmico e estrutural", sendo prescrições de como proceder na coordenação do trabalho coletivo.

No processo administrativo, o controle e a supervisão são os mais utilizados pelas enfermeiras de centro cirúrgico. Os aspectos que consideramos neste item são referentes à escala de funcionários (escala de serviço diário, controle de folgas, férias, faltas, bem como da sala de cirurgia escalada)... quanto ao material se está adequado para a cirurgia"... e se o equipamento está em funcionamento e é adequado". O processo administrativo é um meio que a enfermeira utiliza para coordenar o trabalho coletivo, que é o cuidar do paciente durante do ato cirúrgico. No objeto "administrar" em algumas falas das enfermeiras, não há um planejamento para a prática administrativa, havendo um distanciamento entre as verdadeiras necessidades do serviço e a prática realizada.

Observamos que o cuidado ao paciente ressalta-se nas representações das enfermeiras, mas é um cuidado indireto, sendo este manifestado pela preocupação com o ambiente, o mais organizado possível e o material deve ser esterilizado de maneira mais correta, enfim a preocupação com o paciente passa através de outras atividades subjacentes ao cuidado direto. 


\section{CONSIDERAÇÕES FINAIS}

A análise permitiu-nos apreender o trabalho da enfermagem em centro cirúrgico, no ano de 1988, o qual estava voltado para organização do ambiente em que o doente estava inserido, o cuidado indireto e o administrar o centro cirúrgico.

Com relação à finalidade consideramos como sendo a organização do ambiente em centro cirúrgico, cujo produto é manter o paciente no ambiente de sala de cirurgia livre de infecções, promovendo dessa forma um ambiente mais adequado possível.

Os instrumentos de trabalho identificados pela enfermeira de centro cirúrgico foram: o conhecimento, a observação, a comunicação, normas e rotinas, o bom senso, o controle e a supervisão.

Notamos que, as enfermeiras se preocupam com a solicitação da equipe médica do que propriamente com questão administrativa, que é um dos principais instrumentos de trabalho da enfermeira de centro cirúrgico e, que no nosso entender deve ser melhor estudado para que haja uma aplicação prática mais efetiva desse processo de trabalho.

The authors relate in paper the working process of the nursing from the operation room that is it, the working objects, the instruments, the production and their finalities.

Uniterms: Work's process, nurse, operation room in nursing.

Los autores relatan en este artículo el trabajo de la enfermera en el centro quirúrgico, o sea los objetos de trabajo, los instrumentos, el producto y sus finalidades.

Unitermos: proceso del trabajo, enfermera, enfermería en centro quirúrgico.

\section{Referências Bibliográficas}

01. ALCÂNTRA, G. A enfermagem moderna como categoria profissional: obstáculos à sua expansão na sociedade brasileira. Ribeirão Preto. 125p. Tese (Cátedra) - Escola de Enfermagem, Universidade de São Paulo, 1963. 
02. ALMEIDA, M.C.P. A prática da enfermagem como subsídio para a formação enfermeiro. In: A PRÁTICA DA ENFERMAGEM E O CURRÍCULO DE GRADUAÇÃO, 1985, Ribeirão Preto. Anais. Ribeirão Preto: Escola de Enfermagem de Ribeirão Preto, Universidade de São Paulo, 1985. p. 53-59.

03. ALMEIDA, M.C.P.; ROCHA, U.S.Y. O saber da enfermagem e sua dimensão prática. São Paulo: Cortez, 1986.

04. ALMEIDA, M.C.P. et. al. A situação da enfermagem nos anos 90. In: CONGRESSO BRASILEIRO DE ENFERMAGEM , 41., 1989. Florianópolis. Anais. Florianópolis, Associação Brasileira de Enfermagem, 1989. p 43.

05. CARVALHO, V.; CASTRO I.B. Reflexo sobre a prática de enfermagem. In: CONGRESSO BRASILEIRO DE ENFERMAGEM, 30, 1979. Fortaleza. Anais. Fortaleza, Associação Brasileira de Enfermagem, 1979. p 31.

06. CASTELLANOS, B.E.P. O trabalho do enfermeiro: a procura e o encontro de um caminho para o seu estudo: da abordagem mecânico-funcionalista à pesquisa emancipatória. São Paulo. 395 p. Tese (Doutorado) - Escola de Enfermagem, Universidade de São Paulo, 1987.

07. CASTELLANOS, B.E.P. et. al. Os desafios da enfermagem nos anos 90. In: CONGRESSO BRASILEIRO DE ENFERMAGEM, 41.; 1989. Florianópolis. Anais. Associação Brasileira de Enfermagem, 1989. p.147.

08. CORREIA, T.T.; LEITE, M. Novo processo de supervisão de enfermagem hospitalar. IN: CONGRESSO BRASILEIRO DE ENFERMAGEM, 30.,1978, Belém. Anais. Brasília: Associação Brasileira de Enfermagem, 1978. p. 165-176.

09. DANNA, M.F.; MATTOS, M.A. Ensinando observação: uma introdução. 2. ed. São Paulo: Edicom, 1984.

10. FAYOL, H. Administração industrial e geral. Tradução de Irene Boyano e Maria de Souza. 7. ed. São Paulo: Atlas, 1968.

11. JOUCLAS, V.M.G. Análise da função do circulante de sala de operações de acordo com a metodologia sistêmica de organização de recursos humanos. São Paulo. 214 p. Tese (Doutorado) - Escola de Enfermagem, Universidade de São Paulo, 1987. 
12. MAGNANI, J.C.G. Discurso e representação, ou de como os baloma de kiriurna podem reencarnar-se nas atuais pesquisas. In: CARDOSO, Ruth C. L. (Org.) A aventura antropológica: teoria e pesquisa. Rio de Janeiro: Paz e Terra, 1986.

13. MARX, K. O capital: crítica da economia política. Tradução de Regis Barbosa e Flávio R. Köthe. 2. ed. São Paulo, 1985.

14. MENDES-GONÇALVES, R.B. O processo de trabalho de saúde. São Paulo; Faculdade de Medicina da Universidade de São Paulo/Departamento de Medicina Preventiva, 198831 p (Mimeografado).

15. MINAYO, M.C. de S. O desafio do conhecimento; pesquisa qualitativa em saúde. São Paulo, Hucetec/Abrasco, 1992.

16. TREVISAN, M.A. Enfermagem hospitalar: administração \& burocracia. Brasília: Ed. Universidade de Brasília, 1988. 